\title{
Pengembangan otomasi perpustakaan Universitas Islam Negeri Sumatera Utara Medan berbasis (RADIO FREQUENCY IDENTIFICATION)
}

Triana Santi

\begin{abstract}
This paper describes the development of RFID-based Medan North Sumatra State University (UINSU) library. The development of RFID in the UINSU library is part of an effort in making efforts to increase libraries to become effective and efficient libraries in the education process. RFID is a technology that is very useful and has strengths and strengths or also called "powerful emerging technology" because an institution or college can achieve the totality of a service and management. The development of RFID-based UINSU library automation is currently very much needed by the library and UINSU Medan users. The development of RFID-based automation makes it easy for library staff to improve librarian performance in the use of information technology. The development of RFID-based library automation is also felt by the users so that it is easy in the circulation service both lending and returning books.
\end{abstract}

Keywords: RFID, library, technology.

\section{Pendahuluan}

\section{Latar Belakang}

Diketahui bahwa perpustakaan semakin hari semakin berkembang sesuai dengan kemajuan sebuah teknologi informasi. Perpustakaan yang maju memiliki teknologi informasi agar bisa memberikan pelayanan secara cepat dan mudah, khususnya perpustakaan di universitas, yang diselenggarakan untuk memenuhi kebutuhan masyarakat yang dilayaninya. 
Perpustakaaan Universitas Islam negeri Sumatera Utara adalah sebagai pusat informasi yang dicari oleh mahasiswa dan civitas akademik yang butuh segala informasi. Mahasiswa dan civitas akademik butuh informasi untuk kebutuhannya masingmasing. Mahasiswa dan civitas akademik di mana Universitas memiliki 8 fakultas dan Pasca Sarjana dan tiap-tiap program studi masing-masing membutuhkan informasi yang berbeda-beda sesuai dengan disiplin ilmunya. Dengan adanya program-program studi yang ada di UINSU, untuk itu membuat perpustakaan harus lebih aktif dan memiliki sensitifitas terhadap kebutuhan para pemakai khususnya mahasiswa dan civitas akademik. Untuk itu harapannya dengan berkembangnya prodi-prodi yang ada membuat perpustakaan menjadi tempat yang ideal bagi para civitas akademik UINSU Medan dalam penelusuran informasi sesuai dengan kebutuhan disiplin ilmunya masing-masing.

Selain harus memiliki koleksi yang memadai, perpustakaan perlu memberikan pelayanan yang ideal sehingga pengunjung perpustakaan memiliki keinginan untuk berlama lama di perpustakaan, ruang baca yang memiliki rasa seni, dan nyaman

Setelah dikembangkan suatu sistem dalam identifikasi barcode, muncul suatu teknologi baru dengan nama RFID (Radio Frequency Identification) yang sangat berkembang maju secara pesat. RFID adalah sebuah teknologi yang sangat bermanfaaat dan memiliki kekuatan dan kelebihan atau disebut juga dengan "powerful emerging technology" karena suatu institusi ataupun perguruan tinggi bisa mencapai totalitas suatu pelayanan dan manajemen. Sebuah lembaga bisa lebih optimal dalam proses 
bisnis dan mereduksi biaya operasional dengan adanya teknologi RFID ketika mengetahui identitas, lokasi, kondisi asset, tools, lainnya. Untuk itu suatu lembaga bisa lebih optimal dalam proses bisnis dan mereduksi biaya operasionalnya yang didukung oleh teknologi RFID.

Perpustakaan berupaya melakukan ikhtiar untuk meniningkatkannya perpustakaan menjadi perpustakaan yang efektif dan efesien dalam proses pendidikan. Aplikasi merupakan kelompok file (form, class, report) dengan tujuan agar bisa dilakukannya kegiatan yang tertentu yang saling terkait. RFID (Radio Frequency Identification) merupakan sebuah teknologi yang bisa mengidentifikasi dengan berbasis gelombang radio (Supriyanto, 2008: 158).

RFID bisa diidentifikasi dari segala objek tanpa diperlukannya kontak langsung ketika dalam proses identifikasi. RFID di implimentasikan yang berguna lebih efektif pada lingkungan yang luas dan memiliki akurasi dan kecepatan dalam mengidentifikasi objek. Pada saat ini teknologi informasi menuntut perpustakaan untuk melakukan pengembangan perpustakaan dalam era globalisasi ini agar lebih mudah, cepat dan efesien. Perpustakaan konvensional sudah ditinggalkan saat ini untuk kemajuan perpustakaan.

Pola pikir tentang perpustakaan terjadi dan berubah yakni penyediaan koleksi yang dimiliki ke arah konsep dalam memberikan informasi, telah menjadikan jalinan kerjasama antar perpustakaan dalam menampilkan koleksi yang dapat memudahkan penyampaian informasi, semakin mudah untuk 
diwujudkan, apalagi dengan adanya perkembangan sistem RFID yang dipakai dalam perpustakaan. Pengembangan perpustakaan yang berbasis RFID bagi tenaga pengelola perpustakaan, dapat membantu pekerjaan di perpustakaan melalui fungsi sistem otomasi perpustakaan, sehingga proses pengelolaan perpustakaan lebih efektif dan efisien.

Menurut Addepalli (2014) mengungkapkan dengan adanya dan penggunaan RFID suatu proses dalam sirkulasi misalnya peminjaman buku dan pengembalian buku bisa dilakukan langsung menggunakan sistem informasi perpustakaan dan tidak lagi dilakukan secara manual. Menurut Sahoo \& Sharma (2015) mengatakan ketika melakukan transaksi pinjam buku dan dikembalikan suatu buku bisa lebih efesien dengan adanya sistem RFID di perpustakaan agar bisa meningkatkan pelayanan kepada pemustaka. Dalam pembukuan manual ketika melakukan pengelolaan suatu data sangatlah kurang efektif dan efesin karena mengelola suatu data dengan jumlah yang banyak, untuk itu diperlukannya sistem pengelolaan data dalam skala besar.

\section{Kajian Pustaka}

\subsection{Peran Perpustakaan}

Pada saat ini perpustakaan bukan didefinikan lagi sebuah ruangan atau gedung yang dipenuhi dengan tumpukan buku saja. Perpustakaan yang ada terus mengalami kemajuan dan dikembangkan suapaya menjadi salah satu pusat informasi. Perustakaan menjadi sumber informasi misalnya seperti sebagai pendidikan, penelitian, rekreasi, dan pelayanan lainnya Menurut Undang-Undang No. 43 tahun 2007 tentang perpustakaan pada 
Bab I Pasal 1 (Sembiring, 2008: 1) mengatakan suatu perpustakaan ialah sebuah lembaga yang mengelola koleksikoleksi berupa karya tulis, karya cetak, dan karya rekam secara profesional dan sistematis dengan sistem yang baku untuk bisa memenuhi kebutuhan informasi, pendidikan, penelitian, dan pelestarian.

Peran dari sebuah perpustakaan ialah suatu bagian dari tugas pokok yang harus dijalankan di dalam perpustakaan. Peran suatu perpustakaan sangat erat hubungannya dengan kegiatan yang harus dilakukan. Peran tersebut masyarakat akan dapat merasakan manfaat dari kegiatan perpustakaan dikarenakan tiap perpustakaan yang dibangun akan mempunyai makna apabila dapat menjalankan peranannya dengan sebaik-baiknya.

Menurut Sutarno (2005: 60) peran sebuah perpustakaan ialah menjadi suatu peran yang penting untuk melakukan perubahan dan pembangunan dalam mengembangkan ilmu pengetahuan dan teknologi informasi. Menurut Sutarno (2006: 68) sebuah perpustakaan memiliki peran yang penting untuk bisa dijalankan yakni: sumber informasi, rekreasi, pendidikan, penelitian, preservasi dan berperan sebagai pembimbing dan memberikan konsultasi kepada pemakai atau melakukan pendidikan pemakai (users education), dan pembinaan serta menanamkan pemahaman tentang pentingnya perpustakaan bagi orang banyak.

\subsection{RFID}

Menurut Erwin (2004: 7) RFID merupakan sebuah teknologi yang menggunakan frekuensi radio untuk mengindentifikasi suatu 
barang atau manusia. Menurut Kania (2011: 16), sebuah RFID merupakan sistem yang memiliki 3 komponen yakni: RFID Tag, RFID Terminal Reader, dan Middleware. Jenis RFID juga ada yakni berdasarkan frekuensi, berdasarkan sumber energi, dan berdasarkan bentuk. Pada saat yang lalu barcode merupakan suatu satu cara dalam melacak atau mengidentifikasi sebuah koleksi yang ada di perpustakaan namun pada saat ini sebuah teknologi baru yakni RFID merupakan suatu teknologi pilihan untuk melakukan identifikasi koleksi yang ada di perpustakaan. RFID mampu membaca ketika sistem RFID aktif.

Menurut Maryono (2005: 19), suatu barcode dan RFID dalam hal ini dua-duanya mempunyai suatu teknologi dalam mengidentifikasi secara cepat dan mempunyai kemampuan dalam melacak secara tepat. Namun ada perbedaannya dimana hanya berbeda ketika scan/ pembaca. Sebuah teknologi barcode bisa membaca label dengan laser optik atau teknologi image. Pada teknologi RFID membaca label dengan sinyal frekuensi radio.

Menurut Supandri (2004) ada beberapa kelebihan RFID dari sistem barcode yakni memungkinkan data dapat dibaca secara otomatis tanpa memperhatikan garis arah bacaan, melewati bahan nonconductor seperti buku, majalah, naskah, compact disc (CD) dan koleksi perpustakaan lainya dengan kecepatan akses beberapa ratus tag setiap detik pada jarak \pm 100 meter. Tag RFID terbuat dari microchip berbahan dasar silikon yang memiliki kemampuan fungsi identifikasi sederhana yang disatukan dalam satu desain. Perpustakaan perguruan tinggi, perpustakaan daerah dan lainnya sudah banyak yang menerapkan RFID. Teknologi berbasis RFID memiliki perkembangan yang sangat pesat dan 
maju karena saat ini orang-orang sangat butuh teknologi RFID. RFID ialah suatu teknologi penangkapan data yang bisa pergunakan secara elektronik untuk mengindentifikasi, melacak dan menyimpan informasi yang tersimpan dalam tag RFID (Wilhusen, 2005).

\section{Pembahasan}

\section{Pengembangan Otomasi Perpustakaan Berbasis RFID}

Pengembangan otomasi perpustakaan UINSU berbasis RFID saat ini sangat dibutuhkan oleh pihak perpustakaan dan para pemustaka UINSU Medan. Pengembangan otomasi berbasis RFID memudahkan para staf perpustakaan untuk meningkatkan kinerja pustakawan dalam penggunaan teknologi informasi. Pengembangan otomasi perpustakaan berbasis RFID juga dirasakan oleh para pemustaka agar mudah dalam pelayanan sirkulasi baik itu peminjaman dan pengembalian buku.

Perpustakaan UINSU akan mengembangkan teknologi informasi berbasis RFID. Pada saat ini perpustakaan UINSU sudah menggunakan sistem otomasi perpustakaan yakni memiliki aplikasi sistem informasi perpustakaan yang merupakan database manajemen perpustakaan. Peminjaman dan pengembalian pun sudah secara online menggunakan kartu perpustakaan dengan menscan barcode kartu perpustakaan. Koleksi buku yang ada di perpustakaan juga telah ditempelkan barcode agar peminjaman dan pengembalian yang dilakukan bisa terintegrasi. Perpustakaan juga memiliki gate pintu masuk dan pintu keluar perpustakaan. Gate pintu masuk perpustakaan UINSU, para pemustaka harus mengetik nomor NIM ataupun menscan barcode kartu perpustakaan untuk masuk ke dalam perpustakaan. Hal tersebut 
sangat berguna untuk melihat jumlah statistik pengunjung setiap harinya.

Sistem informasi perpustakaan UINSU akan di integrasikan dengan sistem RFID yang akan digunakan. Database sistem informasi perpustakaan UINSU di integrasikan berbasis RFID. Mulai dari hardware dan software yang mendukung dalam pengembangan sistem teknologi informasi berbasis RFID.

RFID merupakan suatu cara dalam mengidentifikasi yang menggunakan sarana yakni sebuah label RFID atau transponder untuk menyimpan dan mengambil data jarak jauh. Label atau kartu RFID ialah suatu benda yang bisa dipasang ke dalam sebuah produk, hewan atau bahkan manusia yang bertujuan untuk mengidentifikasi menggunakan gelombang radio. Informasi yang disimpan secara elektronik bisa terbaca sampai beberapa meterdengan adanya label RFID. Sistem pembaca RFID tidak memerlukan kontak langsung seperti sistem pembaca kode batang (barcode).

\section{Penerapan RFID}

Dalam penerapan RFID tidak dibutuhkan lagi layanan sirkulasi melalui tatap muka dengan para staf perpustakaan namun pemustaka berhadapan langsung dengan mesin atau teknologi informasi yang dinamakan dengan selfcheck (peminjaman dan pemgembalian mandiri). Peran staf perpustakaan disini hanya sebagai mengawasi apabila ada kendala pada saat menggunakan teknologi selfcheck. Denga adanya teknologi ini para pemustaka bisa lebih mudah dan menambah pengetahuan baru tentang teknologi dan layanan yang ada di perpustakaan. 
Penerapan RFID di perpustakaan merupakan hal yan baik dalam memberikan kualitas suatu perpustakaan dalam menggukan teknologi. Hal yang terpenting dalam penerapan RFID ini membuat perpustakaan lebih canggih dalam mengelola perpustakaan. Perpustakaan tidak dipandang lagi sebagai sebuah tempat yang hanya menyimpan buku-buku lama, tidak sistematis, masih manual dan lainnya. Untuk itu dengan kehadiran RFID ini, baik itu para staf perpustakaan dan pemustaka mendapatkan pengetahuan dan ilmu baru dalam penggunaan teknologi RFID.

Ada beberapa manfaat dari teknologi informasi untuk aktivitas di perpustakaan yakni: meringankan pekerjaan staf perpustakaan, mempermudah dan melancarkan kinerja pustakawan, memudahkan dan mempelancar pelaksanaan tugas kepustakawanan, proses temu kembali lebih cepat dan tepat, pelayanan informasi lebih meningkat dan bisa memanfaatkan teknologi informasi.

\section{Pemanfaatan RFID di Perpustakaan}

Dulu dan pada saat sekarang masih banyak yang menggunakan barcode karena merupakan suatu cara dalam pelacakan buku. Dengan kemajuan teknologi informasi sistem RFID menjadi salah satu teknologi pilihan dalam mengidentifikasi dan tracking buku, karya ilmiah dan lainnya. Pemanfaatan penggunaan RFID ialah mampu dalam baca tulis dari system RFID aktif yang bisa dimungkinkan seorang pengguna menggunakan pengunaan aplikasi secara interaktif. Lain hal, tag juga bisa membaca dari jarak jauh. Perpustakaan akhir-akhir ini memiliki gagasan untuk menggunakan teknologi RFID di perpustakaan dalam mendukung kinerja dan meningkatkan pelayanan. 
Pemanfaatan RFID untuk perpustakaan saat ini adalah sangat dibutuhkan dalam era globalisasi dan kemajuan teknologi informasi. RFID sangat bermanfaat bagi perpustakaan dikarenakan bisa mendukung kinerja para staf perpustakaan. RFID sangat bermanfaat bagi para pustakawan supaya pustakawan lebih interaktif dalam menggunakan teknologi RFID. Pustakawan menggunakan teknologi bermanfaat untuk meningkatkan pengetahuan dalam penggunaan teknologi. Teknologi yang semakin lama semakin berkembang mau tidak mau para pustakawan harus mampu bersaing, belajar dan mengelola suatu teknologi informasi.

\section{Faktor Kendala Otomasi Perpustakaan Berbasis RFID}

\section{Kendala dalam penerapan RFID}

Untuk menerapkan RFID di perpustakaan perlu dibutuhkan middleware yang efisien dengan data, data pribadi pengguna dan standarnya. Ada sebuah kekuatiran pada privasi pemustaka. ada dua hal yang di khawatirkan dalam pengunaan RFID bagi para pemustaka yakni pelacakan tersembunyi dan mengumpulkan data secara sembunyi-sembunyi. RFID langsung memberikan respon interogasi reader dan tidak menginformasikan kepada pemiliknya yang sah oleh sebab apabila melakukan scanning secara sembunyi-sembunyi dikarenakan bukan pemilik kartu anggota yang sah maka itu merupakan juga bisa menjadi ancaman.

Ada ancaman pada privasi bisa terlihat pada saat nomor seri tag dikombinasikan dengan informasi pribadi. Pada saat didalam dan diluar perpustakaan jaringan reader bisa mengidentifikasi profil anggota perpustakaan. Misalnya pada saat pemustaka 
memakai kartu anggota perpustakaan untuk melakukan peminjaman buku. Pada saat staff perpustakaan yang melayaninya bisa membuat link antara identitas pengguna dengan nomor seri tag yang ada padanya.

\section{Resiko penggunaan RFID}

Ada beberapa resiko dalam penggunaan RFID yakni misalnya gangguan privasi. Gangguan privasi ini bisa menjadi ancaman misalnya gangguang secara fisik yakni tag tersebut tergores, ditukar dan diambil oleh orang. Ancaman lainnya adalah secara tidak langsung ketika seseorang yang bukan pemilik tag yang sah menyamar untuk melakukan modifikasi atau mengubah isi dari tag RFID tersebut

\section{Penutup}

\section{Kesimpulan}

Manfaat dari teknologi informasi di perpustakaan adalah bertujuan untuk pekerjaan para staf perpustakan menjadi ringan, mudah, mendapatkan ilmu baru, melancarkan tugas sebagai pustakawan, temu kembali secara cepat dan tepat, pelayanan informasi menjadi meningkat, dan penggunaan teknologi informasi menjadi bermanfaat.

Pengembangan otomasi di perpustakaan berbasis RFID sangat lah menguntung dan memiliki banyak kelebihan karena RFID merupakan sebuah teknologi baru dalam meningkatkan pelayanan dan kinerja para staf perpustakaan. Pengembangan otomasi perpustakaan menggunakan berbasis RFID harus 
diintegrasikan dengan aplikasi database sistem informasi perpustakaan UINSU.

Dalam pengembangan RFID, pengguna dapat lebih interaktif dalam menggunakan teknologi informasi yang ada di perpustakaan yakni misalnya selfcheck dalam peminjaman dan pengembalian mandiri koleksi yang dibutuhkan oleh pemustaka. Perkembangan perpustakaan dalam teknologi informasi pada zaman sekarang pun sudah semakin berkembang. Dengan berkembangnya zaman dan teknologi informasi perpustakaan maupun para staf perpustakaan wajib ketika yang menggunakan layanan perpustakaan. Secara tidak langsung mau tidak mau harus mengerti paham dalam penggunaan teknologi informasi supaya pengguna bisa memakai sarana, prasarana dan layanan yang disediakan oleh perpustakaan.

\section{Daftar Pustaka}

Addepalli, L. \& Addepalli, G. (2014). Library Management System Using RFID Technology, International Journal of Computer Science and Information Tecnologies, 5(6), 69326935.

Annaraman, Thamarai, P. \& Kumar, K. (2015). Smart Library Management System using RFID, International Journal of Advanced Research in Electrical, Electronics and Instrumentation Engineering, 4(4), 1916-1925.

Dwivedi, Y.K. Kapoor, K.K. Williams, D.J. \& Williams, J. (2013). RFID System in Libraries: An Empirical Examination of Factors Affecting System Use and User Satisfaction, International Journal of Information Management, 33(2), 367-377.

T.Karygiannis, Guidance Securing Radio Frequency Identification (RFID)

Csrt.Nist.Gov/Publikcations/Nistpubs/800- 98/Sp800- 
98_Rfid-2007.Pdf. Diakses Tanggal 5 Oktober 2018 jam 09.00

Maryono, (2005). "Dasar-dasar Radio Frequency Identificatio (RFID) Yang Berpengaruh Di Perpustakaan”. Media Informasi Vol. XIV No. 20. Th. 2005. Soeatminah. 1992. Perpustakaan Kepustakaan dan Pustakawan. Yogyakarta : Kanisius.

Henlia. (2006). "Pengantar Ilmu Teknologi Informasi : Mengenal RFID". $\quad$ www.lib.itb.ac.id/ mahmudin/makalah/ict/ ref/RFID.pdf. 9 Oktober 2011, hal 1.

Erwin. (2004). "Tugas Proyek Mata Kuliah Keamanan Sistem Informasi : RFID”. Departemen Teknik Elektro Fakultas Teknologi Industri Institut Teknologi Bandung. Bandung.

Maryono. (2005). "Dasar-dasar Radio Frequency Identificatio (RFID) Yang Berpengaruh Di Perpustakaan”. Media Informasi Vol. XIV No. 20. Th. 2005.

Sahoo, D.R. \& Sharma, D. (2015). RFID Technology at Central Library, ITT Madras, International Journal of Scientific Engineering and Applied Science, 1(5), 156-172.

Rahardja, U. Frecilia, Y. \& Komaeni, N. (2015). Analisa Peminjaman Buku Perpustakaan Dengan Menggunakan Sistem RFID pada Perguruan Tinggi Raharja, Journal Creative Communication and Innovative Technology, 9 (1), $1-12$.

Santoso, (2014). Perencanaan dan Pembuatan Aplikasi Perpustakaan Berbasis RFID, Jurnal Teknologi \& Industri, 3(1), 47-56.

Sutarno. (2005). Tanggung jawab Perpustakaan: dalam mengembangkan masyarakat informasi. Jakarta: Panta Rei.

Tarigan, ZJH. (2004) Integrasi Technologi RFID dengan teknologi Erp untuk otomasisasi data (Studi kasus pada gudang barang jadi perusahaan furniture, jurnal teknik Industri vol 6 no.2 Desember 2004, Universitas Kristen Petra, Surabaya.

Wilhusen, G. (2005). "Information security key consideration related to federal implementation of Radio Frequency Identification Technology". washington: United States Government Accountability Office. 
